\title{
MAHASISWA HEDONISME NIGHT CLUBBER AND LIFESTYLE (Terhadap Pola Perilaku Mahasiswa Pada Tempat Hiburan Night Club Di Kota Malang)
}

\section{NIGHT CLUBBER HEDONISM STUDENTS AND LIFESTYLE (Towards Student Behavior Patterns at Night Club Entertainment Places in Malang City)}

Diana Febi Anggraini a,1

${ }^{a}$ Fakultas Ilmu Sosial dan Ilmu Politik, Universitas Muhammadiyah Malang

1 dianageli477@gmail.com

\begin{tabular}{l}
\hline Informasi artikel \\
\hline Kata kunci: \\
Dramaturgi, Perilaku, \\
Student, Clubbers, \\
Lifestyle, Hedonism
\end{tabular}
\begin{abstract}
ABSTRAK
Penelitian ini bertujuan untuk mengetahui hubungan antara gaya hidup hedonis dengan perilaku konsumtif pada remaja. Hipotesis dalam penelitian adalah terdapat hubungan positif antara gaya hidup hedonis adanya kebutuhan konsumen akan hiburan yang juga harus dipenuhi. Salah satu hiburan yang ditawarkan adalah tempat hiburan night club yang hingga saat ini masih banyak yang tertarik untuk di kunjungi. Mayoritas pengunjung berasal dari kalangan mahasiswa. Mahasiswa yang melakukan clubbing secara berulang-ulang telah membentuk pola perilaku. Penelitian ini menggunakan teori Erving Goffman tentang Dramaturgi. Penelitian ini menggunakan metode penelitian kepustakaan atau library research Tahapan perkembangan yang terjadi dalam Pola Perilaku Mahasiswa Pada Tempat Hiburan Night Club Di Kota Malang.
\end{abstract}

Hasil dari penelitian ini menunjukkan bahwa terdapat pola perilaku mahasiswa di malang sebagai clubbers sekarang yang terbagi menjadi dua wilayah yaitu dengan panggung depan dan panggung belakang. Pada panggung depan mahasiswa clubbers mempresentasikan dirinya sesuai dengan status sosial yang dimilikinya yaitu sebagai mahasiswa dan sesuai dengan nilai pada umumnya di masyarakat. Selain itu terdapat tim yang dibentuk untuk menjaga pertunjukan di panggung depan. Sedangkan pada panggung belakang terdapat aktivitas yang disembunyikan yaitu aktivitas mengunjungi night club (clubbing) yang rata-rata dilakukan sebanyak 2 sampai 3 kali dalam seminggu. Beberapa aktivitas yang dilakukan di night club antara lain seperti merokok, menikmati lagu, minum alkohol, menari. Masyarakat menganggap aktivitas clubbing merupakan aktivitas negatif. Sehingga menurut masyarakat, mahasiswa tidak pantas melakukan aktivitas tersebut, karena menurut pandangan masyarakat bahwa mahasiswa adalah calon intelektual yang dapat memecahkan permasalahan kehidupan dalam masyarakat menjadi memerlukan perubahan penampilan dan gaya dari panggung belakang ke panggung depan atau sebaliknya, dalam Goffman hal tersebut disebut sebagai manajemen kesan. 
Dramaturgy, Behavior, Student, Clubbers, Lifestyle, Hedonism this study is that there is a positive relationship between the hedonic lifestyle of the consumer's need for entertainment that must also be met. One of the entertainment offered is a night club entertainment venue which until now there are still many who are interested in visiting. The majority of visitors come from students. Students who clubbing repeatedly have formed behavior patterns. This study uses Erving Goffman's theory of Dramaturgy. This study uses the method of library research or library research Stages of developments that occur in Student Behavior Patterns at Night Club Entertainment Places in the City of Malang. The results of this study indicate that there are patterns of student behavior in Malang as Clubbers which are now divided into two regions, namely the front stage and the back stage. On the front stage students clubbers present themselves in accordance with their social status, namely as students and in accordance with the values in general in the community. In addition there is a team formed to guard the show on the front stage.

While on the back stage there is a hidden activity that is the activity of visiting the night club (clubbing), which on average is carried out as much as 2 to 3 times a week. Some of the activities carried out at the night club include smoking, enjoying songs, drinking alcohol, dancing. The community considers clubbing activities as negative activities. So according to the community, students do not deserve to do these activities, because according to the community's view that students are intellectual candidates who can solve life's problems in society. This requires changing their appearance and style from the back stage to the front stage or vice versa, in Goffman it is referred to as management impression.

\section{PENDAHULUAN}

Indonesia merupakan salah satu negara berkembang yang mulai terbawa arus globalisasi. Apalagi sebagian besar masyarakat Indonesia mudah terpengaruhi oleh budaya budaya dari luar baik itu yang merugikan maupun yang menguntungkan.

Berkembangnya teknologi yang semakin canggih dan modernpun menjadi faktor utama dari masuknya budaya-budaya luar, khususnya budaya barat yang terkenal dengan kebebasan yang melampaui batas. Apabila budaya luar yang merugikan dibiarkan masuk begitu saja, maka semakin lama semakin pula moral bangsa Indonesia tercampuri oleh budaya luar yang merugikan. Namun tidak semua negara terbuka dan bisa menerima kebudayan dari luar, dengan alasan mereka masih ingin mempertahankan adat istiadat nenek moyang yang mereka miliki. Mahasiswa adalah salah satu target yang mudah dipengaruhi budaya budaya luar. Hal tersebut dikarenakan mahasiswa memiliki rasa ingin tahu yang tinggi akan hal-hal baru yang masuk ke Indonesia. Mahasiswa 
memiliki daya pikat tersendiri terhadap hal baru tersebut. Sehingga sering kali mahasiswa menerima dengan mudah budaya-budaya barat yang merugikan. Salah satu budaya barat yang merugikan dan sudah banyak yang melekat pada diri mahasiswa adalah hedonisme.(Bruno, 2019)

Gaya hidup merupakan gambaran bagi setiap orang yang mengenakannya dan menggambarkan seberapa besar nilai moral orang tersebut dalam masyarakat disekitarnya, atau juga gaya hidup adalah suatu seni yang dibudayakan oleh setiap orang. Gaya hidup juga sangat berkaitan erat dengan perkembangan zaman dan teknologi. Semakin bertambahnya zaman dan semakin canggihnya teknologi, maka semakin berkembang luas pula penerapan gaya hidup oleh manusia dalam kehidupan Dalam arti lain, gaya hidup dapat memberikan pengaruh positif atau negatif bagi yang menjalankannya. Gaya hidup sering disalahgunakan oleh sebagian besar remaja, apalagi para remaja yang berada dalam kota metropolitan. Mereka cenderung bergaya hidup dengan mengikuti mode masa kini. Tentu saja mode yang mereka tiru adalah mode dari orang barat. Jika mereka dapat memfilter dengan baik dan tepat, maka pengaruhnya juga akan positif. Namun sebaliknya, jika tidak pintar dalam memfilter mode dari orang barat tersebut, maka akan berpengaruh negatif bagi mereka sendiri.

Menurut Kotler gaya hidup adalah pola hidup seseorang di dunia yang diekspersikan dalam aktivitas, minat dan opini. Hal senada juga diungkapkan oleh Widjaja yang menyatakan bahwa gaya hidup sebagai pola hidup yang mengambarkan kegiatan, ketertarikkan, dan opini individu yang berinteraksi dengan orang-orang yang menganut aliran ini, dengan sendirinya menganggap atau menjadikan kesenangan sebagai tujuan hidupnya.10 Gaya hidup hedonis adalah suatu pola hidup yang aktivitasnya untuk mencari kesenangan hidup, seperti lebih banyak menghabiskan waktu diluar rumah, lebih banyak bermain, senang pada keramaian kota, senang membeli barang 5 mahal yang disenanginya, serta selalu ingin menjadi pusat perhatian.

Hedonisme adalah sikap yang mementingkan dan mencari kesenangan duniawi semata meskipun dengan berbagai cara. Hedonisme ini merupakan infiltrasi dari budaya liberal yang berhasil masuk dengan mudahnya ke budaya Indonesia. Budaya ini dapat berupa gaya hidup mewah yang berlebihan, konsumtif, mengikuti gaya-gaya trending yang sedang terjadi, bahkan pergaulan bebas yang orientasinya 
hanya untuk mencari kesenangan semata. Mahasiswa yang sudah terkena penyakit hedonisme ini, sebagian besar akan menjadi mahasiswa yang apatis, konsumtif, bermalas-malasan, dan menghalalkan segala cara untuk kesenangan. Jika masalah ini dibiarkan terus menerus, maka hal tersebut akan merusak nilai-nilai luhur budaya Indonesia, dan akan menyebabkan kesenjangan sosial yaitu yang kaya makin kaya dan yang miskin makin miskin. Padahal mahasiswa adalah generasi penerus bangsa yang seharusnya menjaga dan melestarikan nilai -nilai moral bangsa Indonesia. Gaya hidup hedonis juga menyerang kaum mahasiswa yang menyukai kehidupan mewah. Sebagaimana yang dikemukakan oleh Pakar pendidikan yang juga Guru Besar Ilmu Pendidikan Moral Universitas Negeri Semarang, Prof. Masrukhi (2011) dalam kompas.combahwa, saat ini banyak mahasiswa yang berorientasi pada gaya hidup. Lebih lanjut Prof. Masrukhi menyatakan $10 \%$ mahasiswa merupakan mahasiswa idealis sedangkan $90 \%$ merupakan mahasiswa hedonis yang berorientasi pada gaya hidup glamourdan bersenang-senang. Seperti halnya pada mahasiswa Pendidikan IPS memungkinkan memiliki gaya hidup hedonis.
Pada era modernisasi ini, para pebisnis akan bergegas dalam memenuhi kebutuhan masyarakat. Salah satu yang menjadi kebutuhan masyarakat adalah kebutuhan akan hiburan (physiological). Night club menjadi salah satu tempat hiburan yang digemari untuk dikunjungi oleh beberapa kalangan. Night clubmerupakan tempat hiburan yang menawarkan hiburan dengan gaya kehidupan orang barat yang biasanya dibuka pada larut malam. Di dalamnight club terdapat sajian musik yang dipandu oleh disk jockey (DJ) dengan volume yang keras dan terdapat sesuatu yang khas yaitu pencahayaan yang remang-remang beserta kilauan lampu disko yang gemerlap. Selain itu, terdapat sajian minuman dan makanan tertentu yang ditawarkan dalam menu. Minuman yang ditawarkan dominan yang mengandung alkohol dengan berbagai merk dan racikan yang disajikan oleh bar tender. Sampai sekarang mengunjungi night club masih menjadi trend dalam menghabiskan waktu untuk bersenang-senang. Para pengunjung dalam night club tersebut antara lain berasal dari kalangan (1) pelajar yang meskipun ada yang belum berusia $18+$ namun seringkali dapat masuk ke dalam night club untuk bersenang-senang atau agar tidak dianggap ketinggalan jaman. 
Dunia GemerlapMalbon (1999) mendefinisikan dugem sebagai sebuah aktivitas pertunjukan didalam suatu ruangan yang bernuansa redup dengan lampu-lampu dan dengan diiringi musik.Tidak semua mahasiswi tertarik dengankehidupan dunia gemerlap. Masih banyak yang menganggap bahwa dunia gemerlap identik dengan hal-hal negatif. Namun sebaliknya, ada juga mahasiswi yang secara rutin pergi ke tempattempat hiburan malam dan menjadikan dugem sebagai gaya hidup.dengan adanya dunia gemerlap maka akan menjadikan mahasiswa saat ini tertutup dalam dunia halunya dan dapat menyebabnkan penyimpangan.(Anggraini \& Santhoso, 2019; Senduk, 2016)

Mahasiswa adalah insan yang memiliki berbagai dimensi, salah satunya yaitu sebagai generasi muda yang dianggap dapat membantu berusaha menuntaskan permasalahan yang terdapat sesuai dengan realitas. Mahasiswa merupakan bagian dari civitas academica yang harus dididik dan dibina agar memiliki kemampuan dan kualitas yang kompeten dan dapat diperhitungkankarena mereka diharapkan dapat berperan menentukan sejarah perkembangan bangsa Indonesia. Mahasiswa yang dianggap sebagai generasi muda pada tahap dewasa memiliki cara tersendiri untuk bersenang-senang. Cara mereka melakukan aktivitas bersenang-senang tersebut salah satunya terlihat dalam fenomena night club yang juga terjadi di Kota Malang. Mahasiswa lebih tertarik untuk memilih aktivitas dugem atau clubbing (selanjutnya peneliti akan menggunakan istilah clubbing untuk menyebut aktivitas yang dilakukan mahasiswa di night club). Clubbing merupakan suatu aktivitas yang dilakukan di night club pada larut malam. Ketika clubbing beberapa hal yang dilakukan misalnya menikmati musik yang dimainkan oleh DJ, menikmati minuman beralkohol dan sebagaianya. Adanya aktivitas clubbing tersebut dilakukan secara berulang-ulang dengan berbagai tujuan sehingga membentuk pola perilaku. Mahasiswa yang mengunjungi night club (clubbing) berasal dari ekonomi yang kurang mampu sampai dengan yang mampu namun mayoritas berasal dari ekonomi mampu.(Goffman, 2017)

\section{METODE PENELITIAN}

Adapun metode penelitian kajian pustaka atau studi kepustakaan yaitu berisi teori teori yang relevan dengan masalah masalah penelitian. Adapun masalah pada penelitian ini adalah untuk mengetahui "Mahasiswa Night Club Di Kota Malang dalam Perspektif Dramaturgi Erving 
Goffman". Pada bagian ini dilakukan pengkajian mengenai konsep dan teori yang digunakan berdasarkan literatur yang tersedia, terutama dari artikel-artikel yang dipublikasikan dalam berbagai jurnal ilmiah. Tujuan utamanya kajian pustaka adalah mengembangkan aspek teoritis maupun aspek manfaat praktis. Kajian pustaka berfungsi untuk membangun konsep atau teori yang menjadi dasar studi dalam penelitian.

Jenis dan sifat Penelitian Jenis penelitian yang digunakan dalam penelitian ini adalah penelitian research, yakni penelitian yang dilakukan melalui mengumpulkan data atau karya tulis ilmiah yang bertujuan dengan pengumpulan data yang bersifat kepustakaan, atau telaah yang dilaksanakan untuk memecahkan masalah "Mahasiswa Night Club Di Kota Malang dalam Perspektif Dramaturgi Erving Goffman" yang pada dasarnya tertumpu pada penelaahan kritis dan mendalam terhadap bahan-bahan pustaka yang relevan. Sifat penelitian ini termasuk penelitian deskriptif, penelitian deskriptif berfokus pada penjelasan sistematis tentang fakta yang diperoleh saat penelitian.

Metode Pengumpulan Data Adapun metode pengumpuluan data penelitian ini diambil dari sumber data penelitian. Sumber data dalam penelitian ini dibagi menjadi dua, diantaranya: pertama, sumber primer adalah sumber-sumber yang memberikan data secara langsung dari tangan pertama atau merupakan sumber asli. sumber data primer penelitian ini berupa bentuk wawancara dan menganalisis megenai Mahasiswa Night Club Di Kota Malang dalam Perspektif Dramaturgi Erving Goffman. Sumber data sekunder dalam penelitian ini adalah wawancara pada narasumber berapa dilokasi kota malang dan tempat kost.(Anggraini \& Santhoso, 2019; Goffman, 2017)

\section{Tempat dan Waktu Penelitian}

Penelitian ini dilaksanakan di cafe angkringan pojok malang. Penelitian ini dilaksanakan mulai 11 November 2019 sampai 08 Desember 2019,pengambilan data dimulai pada November 2019

\section{Populasi dan Sampel Penelitian}

Populasi penelitian ini adalah mahasiswa Universitas Muhammadiyah Malang angkatan 2015, dan 2016 , 2017, 2018 sebanyak 10 orang. tingkat kesalahan dalam clubber $5 \%$, selanjutya sampel setiap angkatan ditentukan dengan teknik penelitian.

\section{Teknik Analisa Data}

Analisis data yang digunakan adalah analisis isi. Analisis isi (Content Analysis) adalah penelitian yang bersifat pembahasan mendalam terhadap isi suatu informasi studi 
perpustakaan. Adapun teknik analisis data yang digunakan dalam ini sebagai berikut :

a. Penetapan desain atau model penelitian.teknik anaisis data ini ditetapkan beberapa analisis perbandingan atau korelasi, objeknya banyak atau sedikit dan sebagainnya.

b. Pencarian data pokok atau data primer, yaitu teks sendiri dengan sumber yang akurat tentang bentuk dan perkembangan dalam Mahasiswa Night Club Di Kota Malang dalam Perspektif Dramaturgi Erving Goffman Pencarian pengetahuan konstektual dengan mengaitkan satu sama lain antara kajian permasalahan dengan teori yang digunakan

\section{HASIL DAN PEMBAHASAN}

\section{A. Pengertian Hedonisme Night Club}

Hedonisme adalah sikap yang mementingkan dan mencari kesenangan duniawi semata meskipun dengan berbagai cara. Hedonisme ini merupakan infiltrasi dari budaya liberal yang berhasil masuk dengan mudahnya ke budaya Indonesia. Budaya ini dapat berupa gaya hidup mewah yang berlebihan, konsumtif, mengikuti gaya-gaya trending yang sedang terjadi, bahkan pergaulan bebas yang orientasinya hanya untuk mencari kesenangan semata. Mahasiswa yang sudah terkena penyakit hedonisme ini, sebagian besar akan menjadi mahasiswa yang apatis, konsumtif, bermalas-malasan, dan menghalalkan segala cara untuk kesenangan. Jika masalah ini dibiarkan terus menerus, maka hal tersebut akan merusak nilai-nilai luhur budaya Indonesia, dan akan menyebabkan kesenjangan sosial yaitu yang kaya makin kaya dan yang miskin makin miskin. Padahal mahasiswa adalah generasi penerus bangsa yang seharusnya menjaga dan melestarikan nilai -nilai moral bangsa Indonesia. faktor dari dalam diri sendiri (internal) ataupun dari luar (eksternal) :

1. Faktor Internal

Faktor internal atau dari dalam diri sendiri merupakan penyebab hedonisme yang paling utama. Sudah menjadi sifat dasar manusia ingin memiliki kesenangan sebanyak-banyaknya dengan bekerja seringan mungkin Selain itu, manusia juga memiliki sifat dasar tidak pernah puas dengan hal yang sudah dimiliki. Sifat dasar manusia inilah yang menjadi 
penyebab hedonisme dan juga

perilaku konsumerisme.

\section{Faktor Eksternal}

Faktor penyebab hedonisme dari luar yang paling utama adalah arus informas dari luar yang sangat besar atau globalisasi. Kebiasaankebiasaan dan paham orang dari luar negeri yang dianggap bisa membuat senang kemudian diadaptasi oleh masyarakat Indonesia. Dampak Hedonisme Pada Masyarakat.

Night club merupakan tempat hiburan yang menawarkan hiburan dengan gaya kehidupan orang barat yang biasanya dibuka pada larut malam. Di dalamnight club terdapat sajian musik yang dipandu oleh disk jockey (DJ) dengan volume yang keras dan terdapat sesuatu yang khas yaitu pencahayaan yang remang-remang beserta kilauan lampu disko yang gemerlap. Selain itu, terdapat sajian minuman dan makanan tertentu yang ditawarkan dalam menu. Minuman yang ditawarkan dominan yang mengandung alkohol dengan berbagai merk dan racikan yang disajikan oleh bar tender. Begitu juga dengan makanan yang ditawarkan hanya makanan tertentu saja yang ada dalam menu. Sampai sekarang mengunjungi night club masih menjadi trend dalam menghabiskan waktu untuk bersenang-senang. Para pengunjung dalam night club tersebut antara lain berasal dari kalangan pelajar yang meskipun ada yang belum berusia $18+$ namun seringkali dapat masuk ke dalam night club untuk bersenang-senang atau agar tidak dianggap ketinggalan jaman

B. Realitas Mengenai Night Club dan Clubbers di Kota Malang Kota

Malang terkenal dengan sebutan salah satunya sebagai kota pendidikan, terlihat dengan banyaknya perguruan tinggi dan peminat selain mahasiswa yang asli domisili di Malang juga banyak terdapat mahasiswa pendatang yang menetap dalam kurun waktu tertentu di kota tersebut. Sehingga dengan banyaknya pendatang maka Kota Malang berkembang secara ekonomi, budaya dan sosial. Hal tersebut memungkinkan untuk menumbuhkan munculnya tempat hiburan sebagai industri hiburan pendukung. Salah satu tempat 
hiburan yang kerap kali dipilih mahasiswa yaitu tempat hiburan dunia malam (night club). Berikut daftar beberapa night club yang cukup santer di kalangan mahasiswa di Kota Malang antara lain:

(1) night club A, (2) night club B, (3) night club C dan (4) night club D. Night club biasanya berada di basement dekat parking area di mall atau hotel seperti night club $\mathrm{B}$, night club A dan night club D. Namun beberapa dapat juga ditemukan selain di basement seperti night club C. Pada sisi sebelum memasuki pintu night club terdapat resepsionis yang biasanya melayani untuk menginfokan berupa harga tiket masuk (biasa disebut first drink charge/FDC) dan reservasi. Konsep ruang yang terdapat di night club memiliki desain interior yang diterapkan dalam bentuk stylist, tidak banyak menambahkan dekorasi yang rumit. Ketika memasuki night club terdapat panggung di depan, panggung untuk talentketika perform. Talent tersebut antara lain seperti sexy dancer, ladies club, bintang tamu (band, penyanyi dan sebagainya) dan DJ. Disekitar terdapat tempat duduk dan meja untuk para clubbers, ada tempat untuk bar tender serta space di dekat panggung untuk tamu menari.

Adanya lampu disko warna-warni yang disebut lighting dan disco ball yang menjadi khas night club serta pencahayaan yang kurang atau remang-remang. Serta adanya live music yang dimainkan oleh DJ dengan full sound.

Pada night club juga terdapat talent yang berkontribusi meramaikan night club sebagai daya tarik tempat tersebut, antara lain: disk jockey (DJ), ladies club (LC), sexy dancer, band, MC party dan lain-lain. DJ merupakan seseorang yang memainkan atau memutar musik-musik dan menyambungnya dengan variasi tertentu sesuai dengan keahlian DJ tersebut. Musik yang diputar bergenre dance music dengan nada dan beat-beat khas DJ, yang mampu membuat clubbers untuk menari. Aliran musik DJ tersebut antara lain seperti trance, techno, house, dubstep dan lain-lain. Ladies club (LC) dan sexy dancer merupakan penari yang menari di panggung, tampil dengan pakaian yang seksi, full make up dan menari di atas panggung seolah 
mengajak clubbers yang lain agar ikut menari. Band merupakan sekelompok orang yang memainkan berbagai alat musik yang di dalamnya termasuk vokalis, biasanya bintang tamu yang ditampilkan merupakan selingan sebagai salah satu variasi pertunjukan di night club pada waktu tertentu. MC party merupakan orang yang memandu acara di panggung agar acara lebih semarak. Serta terdapat waiter/waiters yang melayani pengunjung jika ingin memesan sesuatu berupa makanan atau minuman dan bar tender yang bertugas meracik minuman dengan teknik tertentu. Di sepanjang malam pada night club terdapat berbagai event yang ditawarkan. Event yang ditawarkan tersebut merupakan bagian dari manajemen night club untuk menarik pengunjung. Terdapat regular event dan special event yang berlaku pada hari senin sampai minggu. (Arini, Hasanah, \& Muhariati, 2016)

\section{Beberapa contoh} pelaksanaan event dibeberapa tempat, antara lain:
(1) night club A terdapat regular event yang dilaksanakan setiap senin sampai dengan hari rabu, seperti: disturbie academia, happy beer dan sebagainya. Sedangkan pada special event terdapat event seperti: shift anniversary, overlap, transcender dan lain-lain, (2) night club B terdapat regular event yang dilaksanakan setiap minggu sampai dengan jumat, seperti:the university par cocktail heaven, playgirl mansion dan lain-lain. Sedangkan pada special event terdapat event seperti: fierce of diva, horoscope monthly dan lain-lain, (3) night club $\mathrm{C}$ terdapat regular event yang dilaksanakan setiap rabu dan sabtu, seperti: smooth academy, saturday famous. Sedangkan pada special event terdapat event seperti: no sexy jo, fabulous dan lan-lain dan (4) night club D terdapat event yang dilaksanakan seperti: the wheels, feel heavly sound of trance, glamodance dan lain-lain

Selanjutnya terdapat dua ungkapan dalam diri individu yang bisa ditampilkan sehingga dapat dilihat oleh penonton. Pada penampilan yangditampilkan oleh clubbers dari ujung kaki sampai 
ujung rambut merupakan ungkapan non verbal. Berikut merupakan ungkapan verbal berupa interaksi verbal antar clubbers. Menurut pengakuan mahasiswa clubbers bahwa adanya perbedaan jika berbaur dengan sesama clubbers dengan yang bukan sesama clubbers. Perbedaan tersebut terlihat pada obrolan yang dibahas dan dilontarkan oleh mereka. adanya gaya berbicara tertentu. Menurut mahasiswa clubbers jika para clubbers berkumpul maka yang dibahas mengenai dunia malam seperti minum alkohol, seks dan sebagainya. Selanjutnya dengan adanya mahasiswa clubbers yang menyukai clubbing, maka terdapat dampak positif dan negatif. Hal positif menurut mahasiswa clubbers antara lain: mendapatkan banyak teman, mendapatkan informasi dariteman atau kenalan dan merasa dapat terpuaskan kebutuhan akan hiburan dengan bersenang-senang di tempat tersebut, mereka dapat have fun di tempat tersebut. Selain memiliki banyak kenalan namun hal lain yang sudah dirasakan menguntungkan bagi diri mahasiswa clubbers yaitu dalam berbagi informasi mengenai dunia malam, misalnya: ciri-ciri minuman yang dengan sengaja diberi narkoba oleh oknum tertentu. (Arini et al., 2016)

Selanjutnya dampak positif lain yang diperoleh ketika clubbing yaitu dapat mengetahui lebih dalam mengenai bagaimana dunia malam di night club. Sedangkan dampak buruk yang dirasakan mahasiswa clubbers menurut pengakuannya yaitu adanya sikap ketagihan sehingga menyebabkan ingin clubbing secara berulang-ulang atau berkelanjutan. Pernyataan tersebut juga diperkuat dengan pernyataan temannya yang mengetahui panggung depandan panggung belakangnya, ia menuturkan bahwa mahasiswa clubbers tersebut sampai tidak bisa lepas dari dunia malam (clubbing). Dampak buruk lainnya yaitu terkait pada kesehatan bahwa aktivitas clubbing dilakukan pada dini hari sampe menjelang pagi yang diketahui merupakan waktu yang sebenarnya digunakan untuk istirahat setelah beraktivitas seharian maka dengan tidak mempergunakan untuk istirahat tersebut akan menganggu jam 
istirahat sehingga mengakibatkan tidak enak badan dan mengantuk karena kurangnya istirahat. Salah satu aktivitas clubbing seperti minum-minuman beralkohol juga tidak baik untuk kesehatan.

$$
\text { Rutinitas clubbing }
$$

mempengaruhi pada perkuliahan mereka. Hal tersebut terlihat dengan seringkali pulang subuh sehingga menganggu jam istirahat. Jadi ketika jam perkuliahan akan merasa ngantuk dan tidak fokus atau konsentrasi sehingga menyebabkan aktivitas menuntut ilmu tidak dilakukan secara maksimal dan efektif. Serta jika terlalu banyak mengkonsumsi minuman beralkohol akan menyebbakan mabuk yang menurutnya tidak bagus dari segi kesehatan. Bagi mahasiswa clubbers yang sudah tidak mengambil mata kuliah tetapi masih memiliki tugas untuk mengerjakan skripsi, dengan rutinitas clubbingnya maka akan mempengaruhi proses dalam pengerjaan skripsi. Dengan adanya panggung depan dan panggung belakang seperti yang diuraikan di atas maka dapat mengetahui ketika penampilan pada panggung depan dan panggung belakang terlihat memiliki perbedaan dalam mempresentasikan diri maka dari itu pemain harus bisa menampilkan pertunjukan sesuai dengan setting. Dalam Goffman hal tersebut disebut manajemen kesan, yaitu suatu teknik yang dilakukan para pemain untuk merubah penampilan dan atribut sesuai dengan setting.(Arini et al., 2016; Sartika \& Hudaniah, 2018; Senduk, 2016)

\section{Pembahasan Hasil Penelitian Wawancara}

Narasumber yang bernama GHITA Umur 25 Tahun Pendidikan terakir S1 Agama Islambeberapa penjelasan dari narasumber Hedonis merupakan paham untuk orang-orang yang mencari kesenangan hidup semata. Dan menurut saya untuk memenuhi gaya hidup yang diangap menarik, sedangkan arti nigt club menurut saya Night Club itu dari kata Clubing yakni sebagai tempat menghilangkan stress, tempat bersosialisasi dengan orang baru dari muda sampai tua.. dan Saya datang ke tempat Night Club 1-2 kali dalam satu minggu, ya karna saya hobby dan menjadi tempat merefresh otak dan fikiran.. ketika 
banyak tugas kuliah dan untuk tempat mencari ide tugas skripsi saya pada sat ditempat yang saya perankan sebagai Of Course, tentunya saya minuma apapu yang berbentuk alcohol , menikmati alunan music Dj. Dengan menurut Kalau sya ketempat itu untuk mencari kesenangan ,enjoy dan membuat fikiran tenang sejenak. Perbedqan dari Clubing itu menurut saya diskotik jaman dulu sih, Kalau Bar yaitu Lounge ( sportnya itu lebih kecil hanya minum-minum saja.. intinya tempat ini tempat yang “ASIK ,ENJOY “ dan tempat untuk menikmati Alkohol dan Music Dj, banyaknya mahasiswa melakukan merubah diri dan hal baru Menurut saya mereka itu penasaran, dan jika yang sudah mengenal mungkin akan dijadikan hobby buat mereka . ada juga factor internal dan eksternal gaya hidup.

\section{SIMPULAN}

Berdasarkan hasil penelitian saya mengenai "Mahasiswa Clubbers dan Dunia Malam dalam Perspektif Dramaturgi Erving Goffman (studi kasus terhadap pola perilaku mahasiswa pada tempat hiburan night club di kota malang)" ini, maka terdapat beberapa hal yang menjadi kesimpulan yaitu pola perilaku mahasiswa clubbers terbagi dalam dua wilayah yaitu panggung depan dan panggung belakang. Pada panggung depan, mahasiswa clubbers berusaha mempresentasikan dirinya sesuai dengan yang diinginkan dan sesuai dengan nilai pada umumnya di masyarakat. Seperti yang dilakukan mahasiswa clubbers di kampus, tempat tinggal dan sebagainya, dimana mahasiswa clubbers tersebut membawa penampilan dan gaya yang sesuai dengan status yang dimilikinya yaitu sebagai mahasiswa, serta terkadang terdapat tim yang berfungsi untuk menjaga penampilannya di panggung depan. Sedangkan panggung belakang mahasiswa clubbers tersebut disembunyikan dari penonton panggung depan, dimana pada panggung belakang terdapat aktivitas mengunjungi night club (clubbing) yang dilakukan oleh mahasiswa clubbers. Diketahui bahwa masyarakat menganggap aktivitas clubbing merupakan aktivitas negatif sehingga menurut masyarakat, mahasiswa tidak npantas melakukan aktivitas tersebut. Dengan adanya hal tersebut maka diperlukan perubahan penampilan dan gaya dari panggung belakang ke panggung depan atau sebaliknya, dalam Goffman hal tersebut disebut sebagai manajemen kesan. 


\section{DAFTAR PUSTAKA}

(Anggraini \& Santhoso, 2019; Arini et al., 2016; Belakang, n.d.; Bisnis, 2016; Bruce, 2013; Bruno, 2019; Goffman, 2017; Goffman et al., n.d.; Nabella et al., 2017; Praditya, 2015; Qibtiyah, Mahmudi, \& Triningtyas, 2017; Saputri \& Rachmatan, 2009; Sartika \& Hudaniah, 2018; Senduk, 2016) Anggraini, R. T., \& Santhoso, F. H. (2019). Hubungan antara Gaya Hidup Hedonis dengan Perilaku Konsumtif pada Remaja. Gadjah Mada Journal of Psychology (GamaJoP), 3(3), 131. https://doi.org/10.22146/gamajop.441 04

Arini, K. P., Hasanah, U., \& Muhariati, M. (2016). Hubungan Antara Pola Asuh Dengan Gaya Hidup Hedonis Pada Remaja. JKKP (Jurnal Kesejahteraan Keluarga Dan Pendidikan), 3(1), 29. https://doi.org/10.21009/jkkp.031.07

Belakang, A. L. (n.d.). (life long learning) . $1-7$.

Bisnis, J. F. (2016). Activities ), (Interest), (Opinion ). 15(01), 54-71.

Bruce, 2011. (2013). 済無No Title No

Title. In Journal of Chemical Information and Modeling (Vol. 53). https://doi.org/10.1017/CBO9781107 415324.004

Bruno, L. (2019). 済無No Title No Title. Journal of Chemical Information and
Modeling, 53(9), 1689-1699.

https://doi.org/10.1017/CBO9781107 415324.004

Goffman, D. E. (2017). EQUILIBRIA PENDIDIKAN Jurnal Ilmiah Pendidikan Ekonomi. 2(1).

Goffman, D. E., Kasus, S., Pola, T., Mahasiswa, P., Tempat, P., \& Night, H. (n.d.). MAHASISWA CLUBBERS DAN DUNIA MALAM DALAM PERSPEKTIF DRAMATURGI ERVING GOFFMAN (Studi Kasus Terhadap Pola Perilaku Mahasiswa Pada Tempat Hiburan Night Club Di Kota Malang). Retrieved from https://media.neliti.com/media/public ations/111538-ID-mahasiswaclubbers-dan-dunia-malam-dalam.pdf Nabella, M. G., Studi, P., Islam, P., Psikologi, F., Islam, U., \& Raden, N. (2017). MAHASISWI MUSLIM $Y A N G$.

Praditya, M. Y. (2015). DUGEM REMAJA PUTRI “ Studi Tentang Gaya Hidup Remaja Putri di Kota Surabaya " Mochamad Yusuf Praditya. 2-19. https://doi.org/10.3233/JAD-130464 Qibtiyah, M., Mahmudi, I., \& Triningtyas, D. A. (2017). Pengaruh gaya hidup hedonisme dan pola asuh autoritatif terhadap penyiapan kehidupan berkeluarga pada remaja. Counsellia: Jurnal Bimbingan Dan Konseling, 
$7(2), 82$.

https://doi.org/10.25273/counsellia.v7

i2.1799

Saputri, A., \& Rachmatan, R. (2009).

Religiusitas Dengan Gaya Hidup

Hedonisme : Sebuah Gambaran Pada

Mahasiswa Universitas Syiah Kuala

Religiosity and Hedonistic Lifestyle :

An Overview at Syiah Kuala

University ( Unsyiah ) Student.

Psikologi, 12, 59-67.

Sartika, Y. D., \& Hudaniah, H. (2018).

Gaya Hidup Hedonis Dan Intensi

Korupsi Pada Mahasiswa Pengurus

Lembaga Intra Kampus. Jurnal

Ilmiah Psikologi Terapan, 6(2), 213.

https://doi.org/10.22219/jipt.v6i2.714

2

Senduk, R. (2016). Perilaku mahasiswi

dalam dunia gemerlap di kota

Manado. Jurnal Holistik, (18), 1-20.

(Nabella et al., 2017)Anggraini, R. T., \&

Santhoso, F. H. (2019). Hubungan

antara Gaya Hidup Hedonis dengan

Perilaku Konsumtif pada Remaja.

Gadjah Mada Journal of Psychology

(GamaJoP), 3(3), 131.

https://doi.org/10.22146/gamajop.441

04

Goffman, D. E. (2017). EQUILIBRIA

PENDIDIKAN Jurnal Ilmiah

Pendidikan Ekonomi. 2(1).

Nabella, M. G., Studi, P., Islam, P.,
Psikologi, F., Islam, U., \& Raden, N.

(2017). MAHASISWI MUSLIM

$Y A N G$.

Sartika, Y. D., \& Hudaniah, H. (2018).

Gaya Hidup Hedonis Dan Intensi

Korupsi Pada Mahasiswa Pengurus

Lembaga Intra Kampus. Jurnal

Ilmiah Psikologi Terapan, 6(2), 213.

https://doi.org/10.22219/jipt.v6i2.714

2

Senduk, R. (2016). Perilaku mahasiswi dalam dunia gemerlap di kota Manado. Jurnal Holistik, (18), 1-20. 